\title{
Susceptibility of soil organic matter fractions to soil erosion under potato-legume intercropping systems in central Kenya
}

\author{
S. Nyawade, N. Karanja, C. Gachene, M. Parker, and E. Schulte-Geldermann
}

\begin{abstract}
Soil organic matter (SOM) losses due to soil erosion may be considered low in continuous potato (Solanum tuberosum L.) cropping systems, but cumulated over time may cause considerable soil degradation. A field study was conducted in Kabete, Kenya, during the 2014 to 2015 rainy seasons to determine the effect of sediment particle size distribution on SOM losses and to assess the SOM fractions most susceptible to soil erosion under potato-legume intercropping systems. The treatments comprised of bare soil, pure potato stand (sole potato), potato + garden pea (Pisum sativa), potato + climbing bean (Phaseolus vulgaris), and potato + dolichos lablab (Lablab purpureus). A combined aggregate size and density fractionation was used to separate the sediment in size classes of aggregates 53 to $250 \mu \mathrm{m}$ and in the sieve fraction $<-53 \mu \mathrm{m}$, while SOM was fractionated into particulate organic matter with a density of 1.65 to $1.85 \mathrm{~g} \mathrm{~cm}^{-3}$ and mineral-associated SOM with a density of $2.60 \mathrm{~g} \mathrm{~cm}^{-3}$. Sediment and organic matter enrichments varied significantly $(p<0.05)$ among the cropping systems and were consistently highest under sole potato and lowest under potato + dolichos. Soil particles were transported mainly as aggregates, with those in the $<53 \mu \mathrm{m}$ size fraction containing primary silt and clay particles. Stable fractions of SOM related positively with silt plus clay particles $(r=0.89 ; p<0.01)$ and accounted for $95 \%$ of the total SOM losses. Vegetal cover $(\beta=-0.10508 ; p=0.001603)$, splash detachment $(\beta=0.00323 ; p=0.039403)$, and their interactive effect $(\beta=-0.27327 ; p=0.027224)$ influenced the amount and composition of SOM fractions at the aggregate level. Dolichos lablab ensured continuity of effective groundcover and protected the organic matter against soil erosion, thus demonstrating the need to integrate indeterminate legume cover crops into potato cropping systems.
\end{abstract}

Key words: cover crops—intercropping—soil aggregates—soil erosion-soil organic matter fractions

\begin{abstract}
Soil erosion by water remains a major challenge in sloping arable lands, causing soil loss at a rate of 75 billion $t y^{-1}$ from the world agricultural systems (Quinton et al. 2001; Pimentel and Burgess 2013). This process has greatest effect on soil organic matter (SOM) due to its low stability and higher concentrations in the topsoil (Nadeu et al.2011). The organic matter losses occur disproportionally as the erosion process is selective, transporting the SOM based on its density and location within the soil matrix (Martínez-Mena et al. 2012; Wang et al. 2013, 2014). These differences are defined by the enrichment ratio with values above unity indicating higher organic matter concentrations in eroded sediment relative to the
\end{abstract}

turnover rates, and respond differently to soil management systems. Physical fractionation procedures including density and particle size have been used to separate the organic matter into stable and labile fractions (Cambardella and Elliot 1992; Six et al. 2002). The stable SOM has higher density and includes well-decomposed microbial products forming organo-mineral complexes with the finer mineral particles making it relatively recalcitrant (Golchin et al. 1994; Christensen 2001; Six et al. 2002). The labile or particulate organic matter is a temporary pool between the fresh incorporated litter and mineral associated carbon (C) (Christensen 2001), which consists of recently incorporated organic materials such as microbial and plant-derived polysaccharides, roots, and fungal hyphae (Six et al. 2001). When this fraction of organic matter gets entrapped within the secondary organo-mineral complexes, it undergoes more decomposition due to its protection within the aggregates and is referred to as occluded particulate organic matter (Christensen 2001). The particulate organic matter has a light density, and its decomposition rate determines the nutrient availability to plants (Kapkiyai et al. 1999; Balesdent et al. 2000).

While some authors relating eroded sediment to SOM concentrations contend that water erosion transports mainly the labile fractions of SOM due to its relatively lower density (Owens et al. 2002; Jacinthe et al. 2002; Zhang et al. 2006; Wang et al. 2014), others have shown that the main SOM pool mobilized by erosion is the most stable C (Golchin et al. 1998; Berhe 2012; Wang et al. 2013). Martínez-Mena et al. (2008) concluded that losses of labile SOM in culti-

source soils (Rhoton et al. 2006; Haregeweyn et al. 2008). Depletion of SOM will degrade the soil structure, lower the soil water holding capacity, deteriorate the soil aggregate stability, and compromise the soil fertility (Gachene et al. 2001; Janzen 2004). Losses of $1 \mathrm{mg}$ SOM ha ${ }^{-1}$ were associated with a decrease in wheat (Triticum aestivum L.) yield of approximately $40 \mathrm{~kg}$ grain $\mathrm{ha}^{-1}$, reflecting a $60 \%$ yield decline per unit milligram loss of SOM (Diaz Zorita et al. 1999).

The rate and extent of SOM depletion by physical processes depend not on the total organic matter content, but rather on which size fraction is affected (Puget et al. 2000; Von Lützow et al. 2006; Pikul et al. 2007). These fractions differ in quality, quantity, and
Shadrack Nyawade (corresponding author) is a postdoctoral student at the CGIAR Research Program on Climate Change, Agriculture, and Food Security (CCAFS), University of Nairobi, Nairobi, Kenya. Nancy Karanja is a senior lecturer in the Department of Land Resources Management and Agricultural Technology at the University of Nairobi, Nairobi, Kenya. Charles Gachene is a senior lecturer in the Department of Land Resources Management and Agricultural Technology at the University of Nairobi, Nairobi, Kenya. Monica Parker is a deputy director with the CGIAR Research Program on CCAFS, International Potato Center, Nairobi, Kenya. Elmar Schulte-Geldermann is the director of the International Potato Center for the CGIAR Research Program on Roots, Tubers, and Bananas (RTB), International Potato Center, Nairobi, Kenya. 
vated areas are intensified by the low overall biomass production coupled with the low residue return. In particular, potato cropping systems exacerbate SOM losses by water erosion in sloping arable lands, especially where the crop is established in pure stands because its effective canopy closure exceeding $40 \%$ lasts for a short period and the mulch retained after harvest is insufficient, leaving the soil bare (Chow and Rees 1994; Auerswald et al. 2000). The steep side slopes of the potato mounds concentrate water in the furrows, which detaches soil particles and transports them out of the field (Eshel et al. 2015) while harvest translocates the soil, making it more prone to erosion (Auerswald et al. 2006). In East Africa, high-intensity rainfall events occur early in the seasons before canopy closure and when soil is relatively loose from hilling, which increases soil erosion rates. This study determined the effect of sediment particle size distribution on SOM losses and assessed the SOM fractions most susceptible to soil erosion under potato-legume intercropping systems.

\section{Materials and Methods}

Site Description. This study was conducted at Upper Kabete Research Station of the University of Nairobi during the short rains of 2014 and in the short and long rains of 2015. The site lies along latitude $1^{\circ} 15^{\prime} \mathrm{S}$ and longitude $36^{\circ} 44^{\prime} \mathrm{E}$ at an altitude of 1,809 $\mathrm{m}$ above sea level. Kabete is representative of the agricultural farming systems of East Africa where the main limitation to potato (Solanum tuberosum L.) production is high soil erosion rates. The area has a bimodal distribution of rainfall, with the long rains occurring from early March to late May and the short rains from mid-October to late December. The mean annual rainfall is $1,006 \mathrm{~mm}$ with $50.7 \%$ and $27.5 \%$ of the rain occurring during the long and short rains, respectively (Schmidt et al. 2006). The agro-ecological zonation of the area is described as semihumid (Sombroek et al. 1982). The soil is a typical clay-loam classified as humic nitisol (FAO/UNESCO 1971-1981) and equivalent to alfisols in the USDA soil classification system. These soils are very deep, well drained, dark red friable clay, showing an $\mathrm{ABC}$ sequence of horizon differentiation with clear and smooth boundaries (Schmidt et al. 2006). The topsoil overlies an argillic B horizon and has an erodibility factor of 0.04 (Barber et al. 1979). The area has a rolling topography with slopes ranging between $8 \%$ and 30\% (Barber et al. 1979), making soil erosion by water a major problem, exceeding $247 \mathrm{t} \mathrm{ha}^{-1} \mathrm{y}^{-1}$ (Gachene et al. 1997). The land is mainly used for growing potatoes, grain legumes, and vegetables. The site had prior to the experiment been under two consecutive seasons of continuous maize (Zea mays L.) followed by one season of fallow. Soil property data at start of the experiment are provided in table 1.

Experimental Design and Crop Management. The study was conducted in bounded runoff plots laid out in a randomized complete block design on a $12 \%$ slope. Each plot measured $2.4 \mathrm{~m}$ wide and $5.8 \mathrm{~m}$ long and was laid with the longest dimension parallel to the slope. The treatments comprised of bare soil, pure stand of potato (sole potato), potato + garden pea (Pisum sativa), potato + climbing bean (Phaseolus vulgaris), and potato + dolichos (Lablab purpureus). Shangi potato variety were planted at a spacing of $90 \mathrm{~cm}$ between the rows and $30 \mathrm{~cm}$ within the rows while the legume beans were intercropped in a single row between the rows of potato at a spacing of $25 \mathrm{~cm}$, giving a total of eight rows per plot. Full amounts of $90 \mathrm{~kg}$ nitrogen $(\mathrm{N})$ $\mathrm{ha}^{-1}, 100 \mathrm{~kg}$ phosphorus $(\mathrm{P}) \mathrm{ha}^{-1}$, and $90 \mathrm{~kg}$ potassium $(\mathrm{K}) \mathrm{ha}^{-1}$ fertilizer were applied as basal at planting for potato, while the beans were planted with triple super phosphate $(0: 46: 0)$ at a uniform rate of $50 \mathrm{~kg} \mathrm{P} \mathrm{ha}{ }^{-1}$. The potato crops were sprayed two times (at 14 and 28 days after planting) with Ridomil $(0.4 \%)$ to control early blight infection and three times (at 42, 56, and 70 days after planting) with Dithane-M $45(0.2 \%)$ to control late blight. Malathion (0.2\%) was sprayed on potatoes at 45 and 60 days after planting to control insects. Legume cover crops were sprayed alternately with $0.5 \%$ Bestox pc50 and Duduthrin 1.75 EC (0.3\%) from two weeks after planting and progressively at two-week intervals until the crops attained physiological maturity.

Weeding and hilling were done twice at 10 and 30 days after crop emergence to build up adequate ridges for optimal tuber formation and bulking and to provide protection from potato tuber moth and other pests. Control plots were also hilled up at this time and were kept bare throughout the season by plucking the emerging weeds every 10 days. Weeds from cropped plots were also plucked to avoid introduction of bias. Legume cover crops were harvested by plucking the pods at maturity, leaving the rest of the plant to continue providing postharvest vegetal cover. Potato crops were harvested at maturity by digging out the tubers using hand hoes, retaining the aboveground biomass in the plots. All the dead plant matter was incorporated into the soil at start of the subsequent season.

Sediment Sampling and Analysis. Sediment was collected after each runoff-generating rainfall event according to procedures described by Wendelaar and Purkis (1979). The runoff-sludge mixture was thoroughly stirred, and the resultant suspension allowed to settle for 30 minutes. The runoff water overlying the settled sludge was decanted and measured using a graduated bucket. Sediment concentration was determined by oven-drying a $100 \mathrm{~mL}$ suspension at $105^{\circ} \mathrm{C}$ for 48 hours and expressed as dry soil mass in grams per liter. Total soil loss was computed using equation 1 :

Soil loss $(\mathrm{g})=$ total runoff $(\mathrm{L}) \times$ sediment concentration $\left(\mathrm{g} \mathrm{L}^{-1}\right)$.

Fresh sediment subsamples were airdried, ground, sieved, and stored at $4{ }^{\circ} \mathrm{C}$ for SOM analyses.

Computation of Rainfall Intensity and Kinetic Energy. Total rainfall amount was recorded after every rainstorm event at an agrometeorological station located about $200 \mathrm{~m}$ from the experimental site. Rainfall intensity was computed for each event using equation 2 :

Rainfall intensity $\left(\mathrm{mm} \mathrm{h}^{-1}\right)=$

rainfall amount (mm) ,

rainfall duration $(\mathrm{h})$

while rainfall Kinetic energy (KE) was computed using the Wischmeier and Smith (1958) model equation (equation 3),

$\mathrm{KE}=11.9+11.8 \log I$,

where $I$ is the rainfall intensity in $\mathrm{mm} \mathrm{h}^{-1}$.

Determination of Soil Splash Detachment. Soil splash detachment was measured from each plot using splash cups (Morgan 1978) made of hollow plastic cylinders pushed into the ground so that the top was flush with the soil surface. The cups had a circular catching tray and a partition board dividing the catching tray into upslope and downslope compartments (figure 1). The boundary wall 
size was designed to a height of $20 \mathrm{~cm}$ and a diameter of $20 \mathrm{~cm}$ to prevent splash-in from outside and splash-out from the cup. The cup slope was reduced to nearly $0^{\circ}$ to prevent rainfall from entering the exposed soil area and to exclude runoff effects. The cups were placed in the inter row between potatoes and legumes for the intercropped plots and between two potato rows for the sole potato plots. The soil particles detached by splashing were caught in the catch tray and were collected after each rainfall event and freed from litter fall. The collected samples were ovendried at $105^{\circ} \mathrm{C}$ for 48 hours and expressed as dry soil mass per square meter. The soil splash detachment rate (SD) was calculated using equation 4 :

$\mathrm{SD}\left(\mathrm{kg} \mathrm{m}^{-2}\right)=\left[1-\exp \left(-\frac{\pi}{2} \frac{R}{\Lambda}\right) \frac{2}{\pi} \frac{\Lambda}{R} \mu\right.$,

where $R=$ cup radius (m), $\Lambda=$ average soil splash length in $\mathrm{m}$, and $\mu=$ actual detachment rate in $\left(\mathrm{kg} \mathrm{m}^{-2}\right)$.

Particle Size Separation and Sequential Density Fractionation of Soil Organic Matter. A combined aggregate size and density fractionation was used to separate the sediment and organic matter into size fractions (Camberdella and Elliot 1992; Sohi et al. 2001) (figure 2). Fifty (50) g of the eroded sediment was dispersed by $50 \mathrm{~mL}$ of $5 \%$ sodium hexametaphosphate $\left(\left[\mathrm{NaPO}_{3}\right]_{6}\right)$ made to $250 \mathrm{~mL}$ using $200 \mathrm{~mL}$ deionized water. The sample was shaken overnight and passed through a series of sieves of sizes 250 to $53 \mu \mathrm{m}$ on a mechanical sieve shaker. Sand fractions were retained on sieves $>53$ $\mu \mathrm{m}$ while silt and clay fractions $(<53 \mu \mathrm{m})$ were repeatedly siphoned off. Density separates were recovered by sodiumpolytungstate (SPT) following a density separation procedure modified from Sohi et al. (2001). Twenty (20) g of eroded sediment was suspended in deionized water, stirred, and decanted to retain the organic material. The content was transferred into $250 \mathrm{~mL}$ centrifuge bottle and $125 \mathrm{~mL}$ SPT solution of density 1.65 $\mathrm{g} \mathrm{cm}^{-3}$ was added. The suspension was gently shaken, allowed to settle for 30 minutes, and centrifuged at 2,000 rpm for $30 \mathrm{~min}-$ utes. The supernatant was filtered through a $45 \mu \mathrm{m}$ sieve, and the residue was rinsed with deionized water and referred to as free particulate organic matter (fPOM). Forty (40) $\mathrm{mL}$ of $1.85 \mathrm{~g} \mathrm{~cm}^{-3} \mathrm{SPT}$ solution plus 10 glass beads were added into the settled residue and then centrifuged at $175 \mathrm{rpm}$ for

\section{Table 1}

Soil properties of the site at start of the experiment.

\begin{tabular}{lcccr}
\hline & & \multicolumn{3}{c}{ Soil particle fraction $(\boldsymbol{\mu m})$} \\
\cline { 3 - 5 } Property & Bulk soil & $\mathbf{2 , 0 0 0}$ to $\mathbf{2 5 0}$ & $\mathbf{2 5 0}$ to $\mathbf{5 0}$ & \multicolumn{1}{c}{$<\mathbf{5 0}$} \\
\hline $\mathrm{pH}$ & 5.23 & 5.24 & 5.23 & 5.21 \\
Total OC $\left(\mathrm{g} \mathrm{kg}^{-1}\right)$ & 26.80 & 2.40 & 6.71 & 18.10 \\
Total N $\left(\mathrm{g} \mathrm{kg}^{-1}\right)$ & 2.60 & 0.11 & 0.66 & 1.87 \\
Clay $(\%)$ & 51.12 & 5.18 & 15.11 & 30.81 \\
Silt $(\%)$ & 26.46 & 4.80 & 10.01 & 11.65 \\
Sand $(\%)$ & 22.43 & 10.60 & 9.91 & 1.92 \\
\hline
\end{tabular}

Notes: $\mathrm{OC}=$ organic carbon. $\mathrm{N}=$ nitrogen.
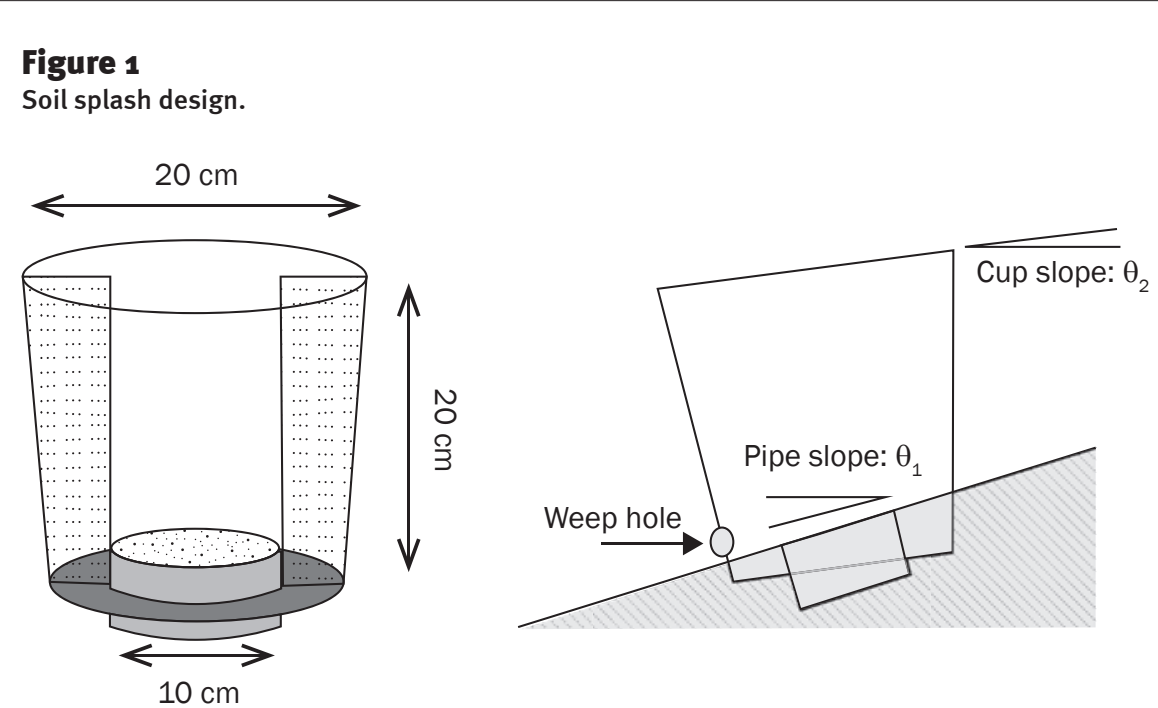

18 hours. The supernatant was filtered, and the retained residue was rinsed and referred to as occluded POM (oPOM). The material that settled was placed in SPT adjusted to a density of $2.60 \mathrm{~g} \mathrm{~cm}^{-3}$, shaken for 10 minutes in an end-over-end shaker, and centrifuged at 3,000 rpm for 30 minutes. The supernatant was decanted, and residue was washed repeatedly with deionized water to remove the residual SPT solution and referred to as the heavy fractions (stable SOM).

Analyses of Soil Organic Carbon and Total Nitrogen from the Aggregates and Density Fractions. Sediment samples from the aggregates and density fractions were ground and total soil organic carbon (SOC) and $\mathrm{N}$ contents were determined by the Walkley-Black (Keeney 1982) and the Kjeldahl digestion (Nelson and Sommers 1982) methods, respectively (equation 5):

OC or $\mathrm{N}\left(\mathrm{g} \mathrm{kg}^{-1}\right.$ soil $)=$ Soil loss $\left(\mathrm{g} \mathrm{kg}^{-1}\right) \times$ Sediment $\mathrm{OC}$ or $\mathrm{N}\left(\mathrm{g} \mathrm{kg}^{-1}\right)$.
Data Management and Statistical Analysis. The data were pooled and subjected to analysis of variance using GenStat, 14th edition (Payne et al. 2009). Means were separated using the protected Fischer's least significant difference test, with differences considered significant at $p \leq 0.05$. Stepwise multiple linear regression analysis was applied on the data set to identify the factors explaining sediment and SOM detachment; vegetal cover, soil aggregate sizes, rainfall kinetic energy, rainfall splash effect, rainfall amount, and rainfall duration were considered as the independent factors.

\section{Results and Discussion}

Rainfall Characteristics during the Study Period. Twenty-seven rainfall events with a total rainfall amount of 1,620 $\mathrm{mm}$ generated soil erosion during the study period (figure $3)$. These events occurred between October 22, 2014, and May 7, 2016, and recorded rainfall amounts ranging from 33 to $104 \mathrm{~mm}$ with maximum rainfall intensities between 


\section{Figure 2}

Schematic diagram of the combined aggregate size and density fractionation.

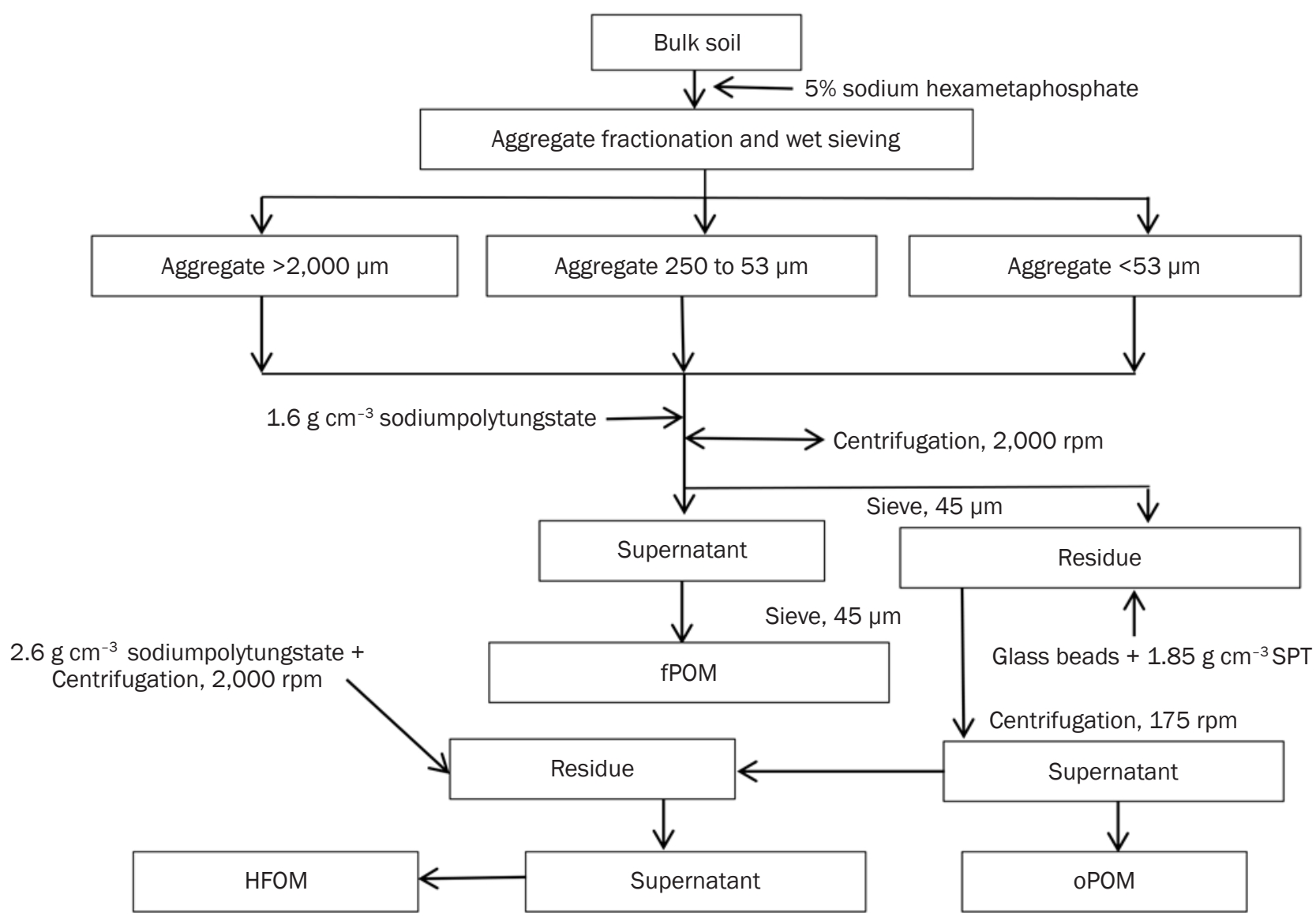

10.87 and $58.36 \mathrm{~mm} \mathrm{~h}^{-1}$. The rainfall kinetic energy during this period was variable and ranged from 23.54 and $74.45 \mathrm{~J} \mathrm{~m}^{-2}$. The eight most intense rainstorms with maximum rainfall intensities between 48.87 and 58.36 $\mathrm{mm} \mathrm{h}^{-1}$ and kinetic energy between 61.29 and $74.45 \mathrm{~J} \mathrm{~m}^{-2}$ generated the largest sediment. These eight events accounted for $80 \%$ to $95 \%$ of the total soil loss recorded during this study period.

Crop Cover Establishment by the Different Cropping Systems. Crop cover development differed among the cropping systems and was generally higher during the 2015 long and short rains compared to the 2014 short rains (figure 4). On average, potato + dolichos plots recorded the highest maximum cover followed by potato + climbing beans, potato + garden pea, and sole potato plots. Crop cover percentage taken at the end of each season and at start of the subsequent season was significant for only potato + dolichos plots.

\section{Figure 3}

Characteristics of the rainfall events during which runoff was collected.

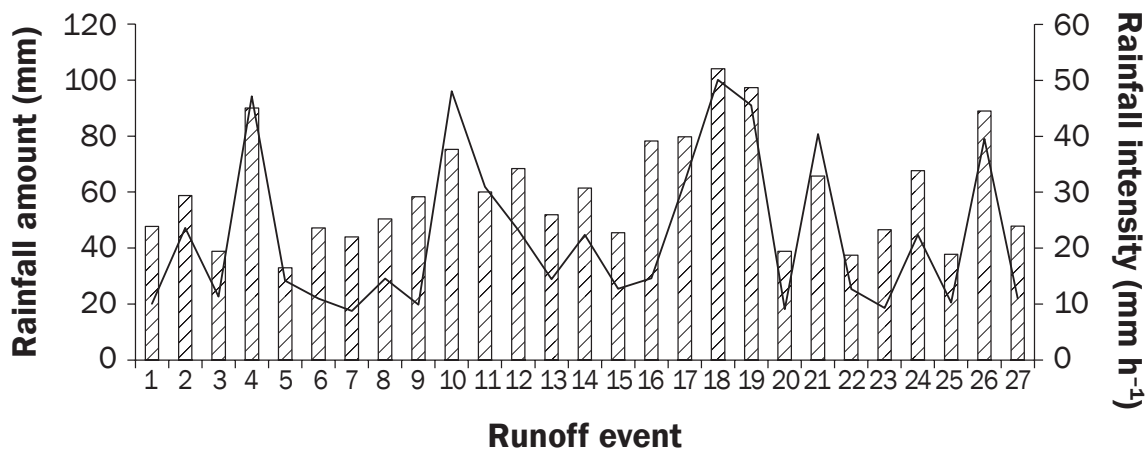

Legend

ए] Rainfall amount (mm) — Rainfall intensity 
Influence of Cropping Systems on Sediment Yield. Mean seasonal soil loss differed significantly among the treatments $(p<0.05)$ and was consistently highest in bare plots and lowest in potato + dolichos plots (table 2). Cumulative soil loss increased by $57.9 \mathrm{t} \mathrm{ha}^{-1}$ and $156.8 \mathrm{t} \mathrm{ha}^{-1}$ from sole potato and bare plots, respectively, compared to potato + dolichos. The sediment enrichment ratios (ER) declined with increase in vegetal cover and were above unity for silt and clay particles, but less than unity for sand particles.

Soil Splash Detachment Characteristics under Different Cropping Systems. Mean soil detachment declined with increasing vegetal cover from $0.986 \mathrm{~kg} \mathrm{~m}^{-2}$ in sole potato plots to $0.098 \mathrm{~kg} \mathrm{~m}^{-2}$ in potato + dolichos (figure 5). Soil detachment was notably higher at the onset of rains before groundcover establishment and after potato harvest when the groundcover dropped to below 30\% in all plots except for the potato + dolichos treatments.

Organic Carbon and Total Nitrogen Contents of the Eroded Soil Organic Matter Fractions. The total $\mathrm{OC}$ and total $\mathrm{N}$ recovered from the eroded sediment were markedly higher in stable organic matter fractions (HFOM) than in the labile fractions (PPOM and oPOM) and increased with declining aggregate size (figure 6). The stable OC (HFOM-OC) ranged between 12.43 and $22.65 \mathrm{~g} \mathrm{~kg}^{-1}$, representing $46 \%$ to $83 \%$ of the total OC, while the mineral associated $\mathrm{N}$ (HFOM-N) ranged from 1.28 to 2.35 $\mathrm{g} \mathrm{kg}^{-1}$, which was $47 \%$ to $87 \%$ of the total $\mathrm{N}$ across the treatments. The labile fractions retained 6.06 to $13.32 \mathrm{~g} \mathrm{~kg}^{-1} \mathrm{OC}$ and 0.40 to $0.94 \mathrm{~g} \mathrm{~kg}^{-1} \mathrm{~N}$, corresponding to $22 \%$ to $39 \%$ of the total OC and $15 \%$ to $35 \%$ of the total $\mathrm{N}$, respectively. Contents of total OC and total $\mathrm{N}$ in stable and labile fractions of SOM were significantly reduced in potato + dolichos treatments compared to other plots. Regardless of treatment, the contents of OC and total $\mathrm{N}$ were notably higher in the fPOM than in the oPOM fractions of the eroded sediment, although the differences were not statistically significant.

Relationship between Soil Organic Matter Fractions and Sediment Concentration. Both the stable (HFOM) and labile (fPOM and oPOM) SOC enrichments decreased exponentially with increasing sediment concentration (figure 7). The relationship was stronger with the stable $\left(R^{2}=0.95 ; p<\right.$ $0.0001)$ than with the labile fractions (oPOM;

\section{Figure 4}

Crop cover development during the study period.

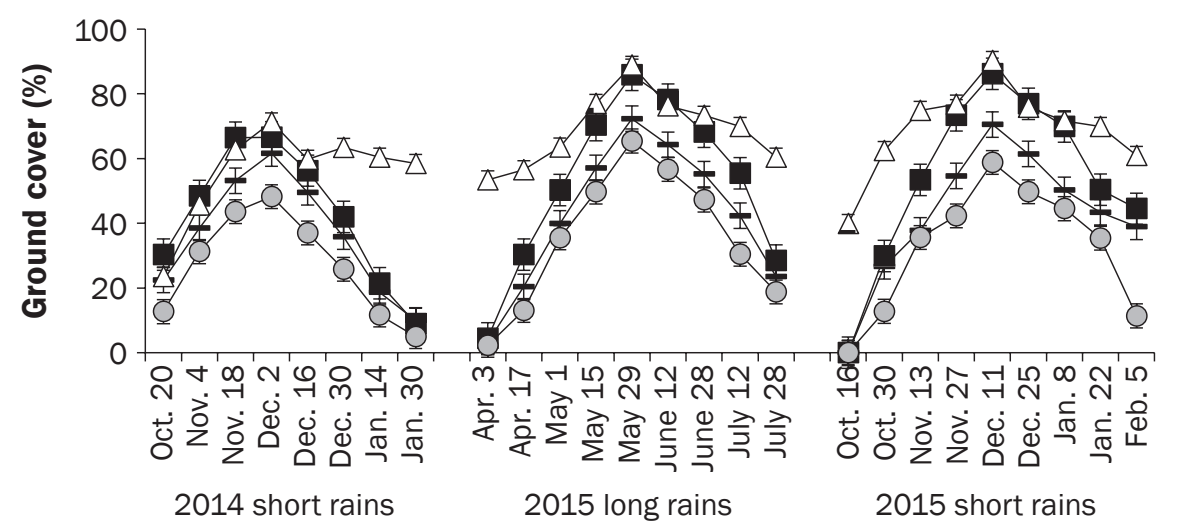

Date after planting for 2014 short rains to end of 2015 long rains

Legend

$\longrightarrow$ Potato + garden pea (T2) $\rightarrow$ Potato + climbing bean (T3)

$\checkmark$ Potato + dolichos (T4) $\quad-0$ Sole potato (T5)

Table 2

Soil loss recorded under different cropping systems.

\begin{tabular}{|c|c|c|c|c|c|c|c|}
\hline \multirow[b]{2}{*}{ Cropping system } & \multicolumn{4}{|c|}{ Soil loss $\left(\mathrm{t} \mathrm{ha}^{-1}\right)$} & \multicolumn{3}{|c|}{ Sediment ER } \\
\hline & 2014 SR & 2015 LR & 2015 SR & Cumulative & Clay & Silt & Sand \\
\hline Bare soil & $20.4 a$ & $66.0 a$ & $88.7 a$ & $175.1 \mathrm{a}$ & 2.2 & 1.9 & 0.9 \\
\hline Potato + garden pea & $7.2 \mathrm{c}$ & $20.3 c$ & $33.3 c$ & $60.8 \mathrm{c}$ & 1.9 & 1.4 & 0.7 \\
\hline Potato + climbing bean & $4.9 d$ & $15.4 d$ & $23.6 d$ & $43.9 d$ & 1.6 & 1.4 & 0.6 \\
\hline Potato + dolichos & $2.5 \mathrm{e}$ & $7.0 \mathrm{e}$ & $8.8 \mathrm{e}$ & $18.3 e$ & 1.3 & 1.1 & 0.4 \\
\hline Sole potato & $9.1 b$ & $24.8 b$ & $42.3 b$ & $76.2 b$ & 1.9 & 1.7 & 0.8 \\
\hline
\end{tabular}

Notes: $\mathrm{SR}=$ short rains. $\mathrm{LR}=$ long rains. $\mathrm{ER}=$ enrichment ratio. Means followed by different letters within a column denote significant differences at $p \leq 0.05$.

$R^{2}=0.55 ; p=0.001 ;$ fPOM; $R^{2}=0.43 ; p=$ $0.0241)$, indicating that much of the eroded sediment was endowed in stable SOM.

Aggregation Ratio of the Eroded Sediment. Aggregation ratios of the eroded sediment decreased with aggregate sizes and were above unity for the macro and messoaggregates and less than unity for the silt plus clay particles (figure 8).

Carbon to Nitrogen Ratio of the Eroded Soil Organic Matter Fractions. The C/N ratios of the eroded SOM decreased with aggregate size of the separated fractions and ranged from 11.3 to 14.9 for the labile fractions and 9.3 to 9.9 for the stable fractions (figure 9).

The stable SOM fractions recorded remarkably lower $\mathrm{C} / \mathrm{N}$ ratio compared to the labile $\mathrm{PPOM}$ and oPOM fractions and showed a higher similarity across the treatments and aggregate sizes. The $\mathrm{C} / \mathrm{N}$ ratio of
fPOM and oPOM showed similarity for a given treatment within the aggregate sizes, but varied across the treatments.

Response of Soil Organic Matter Fractions to Vegetal Cover and Rainfall Characteristics. Soil organic matter contents of the eroded sediment related negatively with vegetal cover $(\beta=-0.105 ; p=0.001603)$ and aggregate size $(\beta=-0.00486$; $p=0.080090)$, but positively with rainfall kinetic energy ( $\beta=$ $0.00836 ; p=0.001483)$ and splash detachment $(\beta=-0.00323 ; p=0.039403)$ (table 3$)$, indicating an increase in SOM contents with increasing rainfall velocity and a decrease with increasing aggregate size and vegetal cover. A significant response of SOM content to combined effect of rainfall splash detachment and vegetal cover $(\beta=-0.00394 ; p$ $=0.020961)$ and vegetal cover and rainfall 


\section{Figure 5}

Cumulative soil splash detachment under different cropping systems. Different lower case letters denote significant differences across the treatments at $p \leq 0.05$. Vertical bars indicate standard error of means.

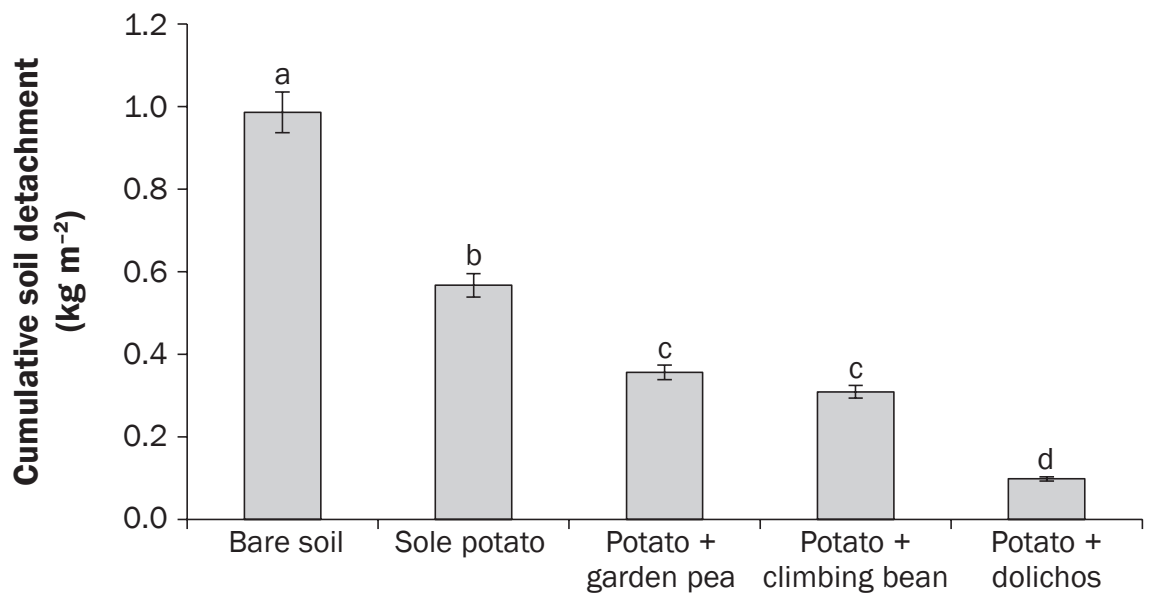

\section{Figure 6}

Soil organic carbon $(\mathrm{OC})$ and nitrogen $(\mathrm{N})$ contents of eroded soil organic matter (SOM) fractions. Bars followed by same letter for each of the aggregate sizes are not significantly different at $p \leq \mathbf{0 . 0 5}$. Error bars denote standard error of means. fPOM signifies free-light particulate organic matter; oPOM signifies occluded-particulate organic matter (FPOM and PPOM are labile); and HFOM signifies heavy fraction organic matter (stable).

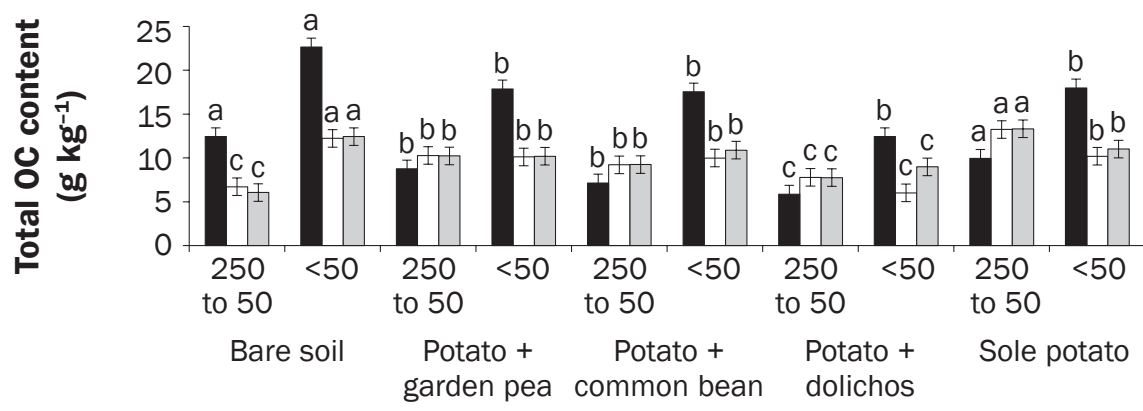

Aggregate size $(\mu \mathrm{m})$

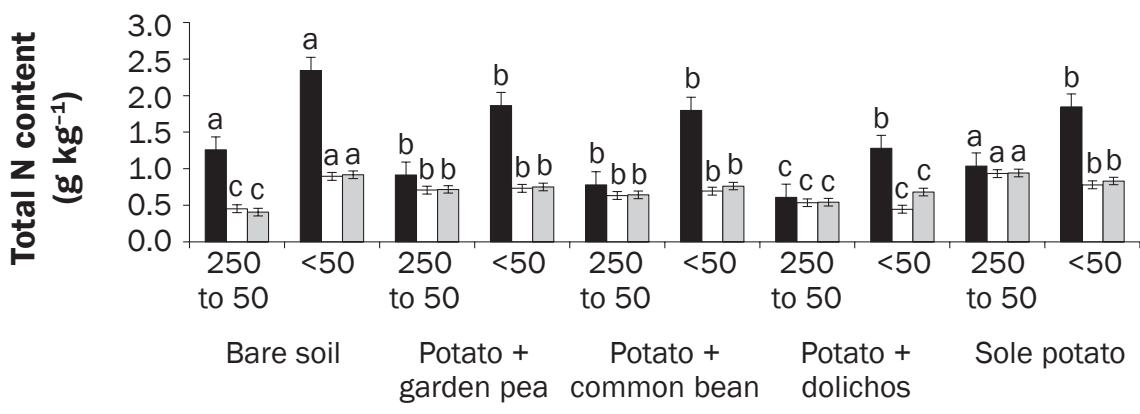

\section{Aggregate size $(\mu \mathrm{m})$}

\section{Legend}

- HFOM $\square$ oPOM $\square$ fPOM kinetic energy $(\beta=-0.27327 ; p=0.027224)$ was found.

Effect of Cropping Systems on Sediment Yield. Sediment yield depended on runoff generation and rainfall kinetic energy, both of which were higher in the unprotected bare plots and lowest under potato + dolichos plots. Crop cover may have reduced the raindrop hitting force and slowed down the runoff velocity, resulting in increased flow depth over the ground surface. This protected the soil aggregates from disruption, thus yielding less sediment. Miao et al. (2011) showed that plant foliage can intercept part of the sediment, thus minimizing their net mobilization by the runoff water. Ma et al. (2015) found that low canopy of some legume cover crops may reduce the raindrop falling height, while their overlap enhances the capability of leaves to resist bending, thus augmenting stem flow. This could support the low sediment yield contributed by dolichos. Crop canopy cover above $40 \%$ has been considered effective in soil erosion control due to its ability to increase the effective rain-receiving area, thus eliminating the effective kinetic energy of rainfall (Khisa et al. 2002). Such canopy cover was contributed by dolichos and was extended after potato harvest to start of the subsequent season. Dolichos exhibited indeterminate growth and tolerated drought conditions prevalent late in the season, which enabled it to contribute effective postharvest and off season vegetal cover. Climbing bean and garden pea attained physiological maturity soon after potato harvest and dried up. The canopy closure of potato was effective only after 40 to 45 days and diminished at physiological maturity when plants began to senesce. Finney (1984) observed that potato canopy is characterized by leaf bending under raindrop impact, creating bare surfaces between the crop rows. The author further noted that this would result in higher energy of dripping water forming at leaf edges under the crop canopy, leading to higher splash erosion.

The higher enrichment ratio of silt and clay particles across the treatments suggests a net enrichment of eroded sediment in fine particles. Boix-Fayos et al. (2015) found that high-energy raindrops disintegrate the macroaggregates producing microaggregates, which are easier to carry into the runoff water. The enrichment ratio varied between the cropping systems, reflecting the role of vegetal cover in aggregate protection. Li et 


\section{Figure 7}

Relationship between soil organic matter (SOM) fractions and sediment concentration. FPOM signifies free-light particulate organic matter; OPOM signifies occluded-particulate organic matter; and HFOM signifies heavy fraction organic matter.

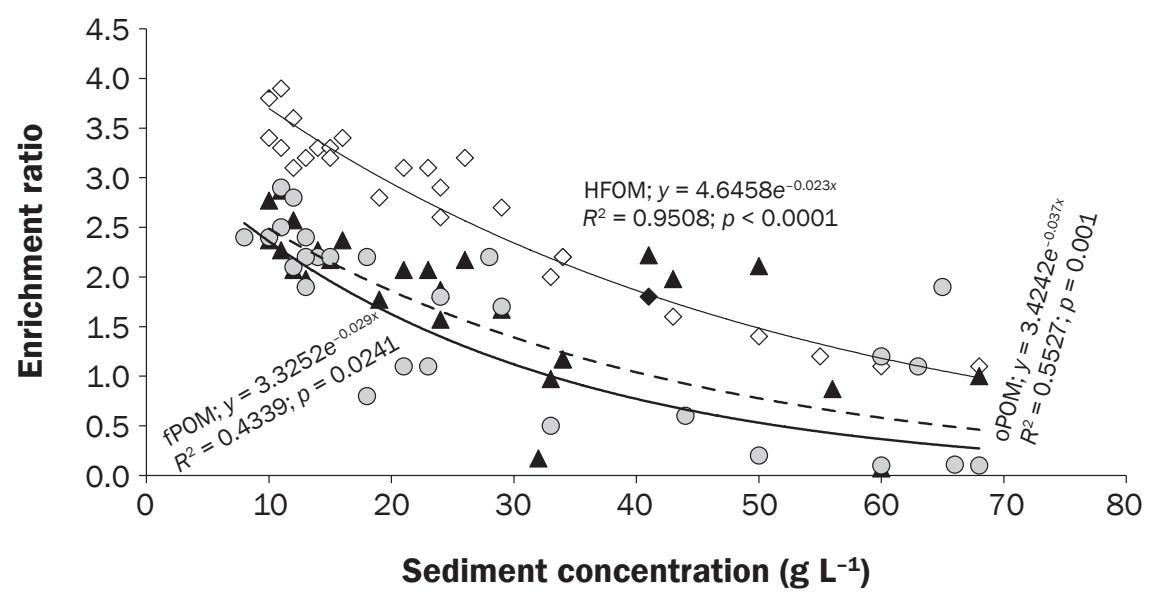

\section{Legend}

$\diamond$ HFOM

$\Delta$ fPOM

O oPOM

\section{Figure 8}

Aggregate ratio for different aggregate sizes.

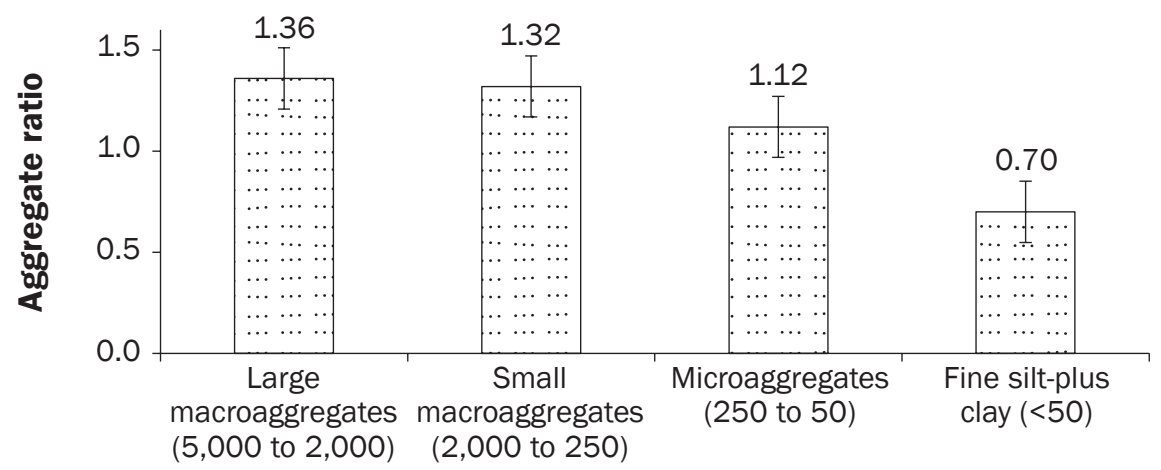

Aggregate size $(\mu \mathrm{m})$

al. (2016) showed that the vegetation cover intercepts the kinetic energy of rainfall, thus shielding the macroaggregates against disruption. This implies that SOM under the crop canopy are available for transport in their more cohesive form, requiring a higher flow transport capacity to be mobilized.

Organic Carbon and Total Nitrogen Contents of the Eroded Soil Organic Matter Fractions. The higher SOM content in stable fractions was probably due to the larger OC and total $\mathrm{N}$ stocks in the finer soil particles. This was denoted by the general increase in OC and total $\mathrm{N}$ contents with decreas- ing aggregate sizes, implying greater physical protection of SOM in the microaggregates. The high specific surface area and numerous reaction sites of the silt plus clay particles (Eustehues et al. 2003) bound the SOC and $\mathrm{N}$, entirely mobilizing them with the eroded sediment. The noticeable lower OC content in the oPOM than in the IPOM fraction may be related to the abundance of iron/ aluminum ( $\mathrm{Fe} / \mathrm{Al}$ ) oxides in nitisols (the soil type in this study) (FAO-ISRIC-ISSS 1998). These ions form microstructures with limited internal volume in relation to their surface area (Roscoe and Buurman 2003), and therefore limits the chances of oPOM remaining protected within the aggregates.

The reduced SOC and total $\mathrm{N}$ content of the eroded SOM under potato + dolichos resonates with the high vegetal cover observed in this treatment. This observation suggests a greater soil stabilizing effect of dolichos, which may be asserted to the continuity of the groundcover throughout the year compared to the other treatments, which were left bare soon after potato harvest. Crop cover type, therefore, had influence on the amount and composition of SOM fractions at the aggregate level. Dolichos produced a low canopy, which reduced the height of throughfall raindrops, minimizing its ability to accumulate splash energy, thus reducing the disruptive effect on soil aggregates.

Relationship between Soil Organic Matter Fractions and Sediment Concentration. The higher enrichment ratio of the mineral bound HFOM compared to PPOM and oPOM for a given sediment concentration implies that soil erosion mainly mobilized the stable SOM. This fraction of organic matter (stable) was associated with the finer silt plus clay, which were dislodged as individual particles by the raindrop impact. Labile fractions were, however, locked up in slightly larger aggregates, which were more difficult to transport. This was exhibited by the aggregation ratio, which was above unity for the aggregate sizes $>53 \mu \mathrm{m}$ and less than unity for the silt plus clay particles $<53 \mu \mathrm{m}$ (figure 8). Bajracharya et al. (2000) argued that the kinetic energy of the raindrops acting together with the shearing force of water runoff disperses aggregates, thus exposing the encapsulated SOM. This process is, however, selective and involves preferential removal of the light and fine soil fractions, which are highly rich in SOM (Gachene et al. 1997). The labile fractions of SOM are, however, associated with the macroaggregates, which require a higher flow transport capacity to be mobilized (Di Stefano et al. 2000). The enrichment of finer silt plus clay particles has been shown to result in higher losses of stable SOM as these particles have a large surface area that possess stronger ability to adsorb the SOM (Wang et al. 2010; Palis et al. 1997). Li and Pang (2014) thus concluded that preferential mobilization of silt and clay particles from cultivated land is the main cause of SOM losses.

The decline in SOM contents with increasing sediment concentration shows 


\section{Figure 9}

Carbon $(\mathrm{C})$ to nitrogen $(\mathrm{N})$ ratio of the eroded soil organic matter (SOM) fractions under different cropping systems. FPOM signifies free-light particulate organic matter; oPOM signifies occluded-particulate organic matter; and HFOM signifies heavy fraction organic matter.

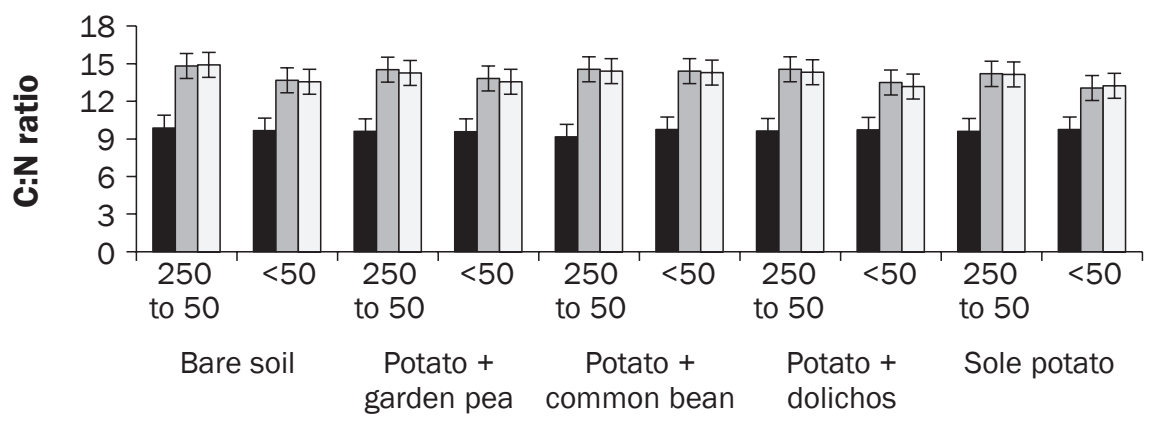

Aggregate size $(\mu \mathrm{m})$

\section{Legend}

- HFOM $\square$ oPOM $\square$ fPOM

\section{Table 3}

Response of soil organic matter (SOM) content to vegetal cover and rainfall characteristics.

\begin{tabular}{lllll}
\hline Dependent variable $=$ SOM content \\
\hline Regression parameter & Coefficients & Standard error & $\boldsymbol{t}$ statistic & $\boldsymbol{p}$-value \\
\hline Intercept & 12.35462 & 3.31044 & 3.73201 & 0.000895 \\
Rainfall kinetic energy (KE) & 0.00836 & 0.00236 & 3.53758 & 0.001483 \\
Splash detachment (SD) & 0.00323 & 0.00149 & 2.16488 & 0.039403 \\
Vegetal cover & -0.10508 & 0.02996 & -3.50742 & 0.001603 \\
Aggregate size & -0.00486 & 0.00267 & -1.81856 & 0.020090 \\
SD $\times$ vegetal cover & -0.00394 & 0.00160 & -2.46411 & 0.020961 \\
KE $\times$ vegetal cover & -0.27327 & 0.11650 & -2.34574 & 0.027224 \\
\hline
\end{tabular}

Notes: $R^{2}=0.99$. Adjusted $R^{2}=0.98$. Standard error $=0.82$.

that SOM export was dependent on erosion intensity with the low-intensity events leading to net transport of microaggregates and high-intensity events favoring mobilization of the heavy macroaggregates. Nevertheless, one would expect SOM loss rates to be positively associated with the sediment concentrations. The most likely explanation for the absence of such an effect is that SOM losses were confounded by other factors such as selectivity in erosion process and the location of organic matter within the soil matrix. The increasing flow aptitude reduced the selective raindrop-induced soil detachment so that the overall macroaggregates disruption increased, resulting in a higher amount of labile SOC and total $\mathrm{N}$ available for transport. This would be in line with the observation of Schiettecatte et al. (2008) and Wang et al. (2013) who showed that increasing flow competence favors flow transport of the coarser grain size fractions, thereby decreasing size selectivity. It may therefore be expected that size selectivity is more closely related to sediment concentration than to absolute soil loss rates, with the low concentrations being linked to the net export of stable SOM.

Carbon to Nitrogen Ratio of the Eroded Soil Organic Matter Fractions. The decreasing $\mathrm{C} / \mathrm{N}$ ratios of the eroded SOM with aggregate size across the treatments shows that these fractions were heterogeneous SOM pools with different composition, age, and location within the soil matrix. The lower $\mathrm{C} / \mathrm{N}$ ratio of the stable SOM reflects a higher degree of microbial processing and state of decomposition of the eroded sediment. This is in accordance with Guggenberger et al. (1994) who showed that this fraction of SOM (stable) resides within the finer silt plus clay particles, which accumulate larger quantity of micro- bial metabolites. Accordingly, higher contents of total $\mathrm{N}$ were recorded in the stable SOM fraction, suggesting a higher mineralization of the eroded sediment. The higher $\mathrm{C} / \mathrm{N}$ ratio of the labile SOM fractions (fPOM and oPOM) in the eroded sediment could be related to the high portion of root-derived litter with low $\mathrm{N}$ contents and points to decreased microbial activity (Yamashita et al. 2006).

The similarity in the $\mathrm{C} / \mathrm{N}$ ratios of heavy fraction organic matter (HFOM) across the treatments suggests that the organic matter in this component were in their recalcitrant state. This observation could be ascribed to the increased $\mathrm{N}$ content partially contributed by the higher microbial activities in this SOM component (Christensen 1996). This result elucidates the role of silt and clay particles in the stabilization of SOM. Differences in the content of SOM across the aggregate classes points to the selectivity of the soil erosion process. These results suggest a more selective detachment and sorting of soil particles during the erosion process, resulting in selective removal of silt and clay particles and the associated stable $\mathrm{C}$ and $\mathrm{N}$.

Response of Soil Organic Matter to Aggregate Sizes, Vegetal Cover, and Rainfall Characteristics. The stronger negative association of SOM contents with vegetal cover implies a decrease of SOM disruption and mobilization under crop canopies. This shows that differences in SOM contents between the cropping systems were caused by the variations in canopy closure. Crop cover dissipated the kinetic energy of rainfall, protecting the aggregates from the hitting impact of raindrops. The significant reduction of SOM with increasing aggregate size of the eroded sediment (as indicated by the inverse relationship) is presumably due to the need of large aggregates to breakdown before appreciable detachment takes place. These aggregates are associated with a stronger cohesive force, which had to be overcome by the rainfall splash to dislodge the organic matter. Thus, unlike the microaggregates that are associated mainly with the stable SOM, the macroaggregates resisted the disruptive effect of rainfall by utilizing part of the rainfall energy to disperse the aggregates. This explains why higher contents of SOM-OC and total $\mathrm{N}$ were recorded in the mineral associated stable fractions. 


\section{Summary and Conclusions}

This study provides a basis upon which the high soil erosion rates in potato cropping systems should be addressed. Sediment yield and organic matter losses occurred mainly at the onset of rains and later after potato harvest, a period which was characterized by low groundcover and high-intensity rainfall events. Dolichos lablab ensured continuity of protective cover throughout the year and protected the soil aggregates against raindrop impact. The high susceptibility of stable SOM fractions to soil erosion was related to its residence in the microaggregates, which were preferentially mobilized as primary particles. The labile SOM fractions were, however, locked up within the macroaggregates, which required greater kinetic energy of rainfall for their disruption to occur, making them less prone to soil erosion.

These findings have implications with respect to the long-term effect of potato cultivation on soil quality. As soil erosion mainly affects the major fraction of organic matter, a rapid depletion of this nutrient may be expected. This will affect other soil properties such as the water holding capacity, soil structure, and aggregate stability, resulting in soil degradation. The ability of legume cover crops to reverse these trends relates to their capability to provide extended canopy cover and control the postharvest soil erosion. Farmers will adopt this practice if it represents an immediate increase in the crop yield and/or net returns. These benefits can only be realized if a careful management of cover crops is ensured to avoid their competition for water, light, and nutrients with the potato crop. This is especially important under tropical rain fed conditions in which there is no possibility of compensating for the excessive water and nutrient consumption.

\section{Acknowledgements}

This research was jointly undertaken under the CGIAR Research Programs on Climate Change, Agriculture and Foods Security (CCAFS); and Roots, Tubers and Bananas (RTB). The authors acknowledge the International Potato Center-Sub-Saharan Africa for supporting this study through grants from the Federal Ministry for Economic Cooperation and Development (BMZ) of Germany.

\section{References}

Auerswald, K., H. Albrecht, M. Kainz, and J. Pfadenhauer. 2000. Principles of sustainable land-use systems developed and evaluated by the Munich Research
Alliance on agro-ecosystems (FAM). Petermanns Geographische Mitteilungen 144:16-25.

Auerswald, K., G. Gerl, and M. Kainz. 2006. Influence of cropping system on harvest erosion under potato. Soil and Tillage Research Journal 89:22-34.

Bajracharya, R., R. Lal, and J.M. Kimble. 2000. Erosion phase effects on $\mathrm{CO}_{2}$ concentration and $\mathrm{CO}_{2}$ flux from an Alfisol. Soil Science Society of America Journal 64:694-700.

Balesdent, J., C. Chenu, and M. Balabane. 2000. Relationship of soil organic matter dynamics to physical protection and tillage. Soil and Tillage Research 53:215-230.

Barber, R.G., TR. Moore, and D.B. Thomas. 1979. The erodibility of two soils from Kenya. Journal of Soil Science 30:579-591.

Berhe, A. 2012. Decomposition of organic substrates at eroding vs. depositional landform positions. International Journal on Plant-Soil Relations 350:261-280.

Boix-Fayos, C., E. Nadeu, J.M. Quiñonero, M. MartínezMena, M. Almagro, and J. de Vente. 2015. Sediment flow paths and associated organic carbon dynamics across a Mediterranean catchment. Hydrological Earth System Science Journal 19:1209-1223.

Cambardella, C.A., and ET. Elliot. 1992. Particulate soil organic-matter changes across a grassland cultivation sequence. Soil Science Society of America Journal 56:777-783.

Chow, T.L., and H.W. Rees. 1994. Effects of potato hilling on water runoff and soil erosion under simulated rainfall. Canadian Journal of Soil Science 74:453-460.

Christensen, B.T. 1996. Carbon in primary and secondary organomineral complexes. In Structure and Organic Matter Storage in Agricultural Soils, ed. M.R Carter and B.A. Stewart, 97-165. Boca Raton: CRC-Lewis-Publishers.

Christensen, B.T. 2001. Physical fractionation of soil and structural and functional complexity in organic matter turnover. European Journal of Soil Science 52:345-353.

Di Stefano, C., V. Ferro, E. Palazzolo, and M. Panno. 2000. Sediment delivery processes and agricultural non-point pollution in a Sicilian Basin. Journal of Agricultural Engeneering Research 77:103-112.

Diaz Zorita, M., D.E. Buschiazzo, and N. Peinemann. 1999. Soil organic matter and wheat productivity in the semiarid Argentinian Pampas. Agronomy Journal 91:276-279.

Eshel, G., R. Egozi,Y. Goldwasser,Y. Kashti, P. Fine, E. Hayut, H. Kazukro, B. Rubin, Z. Dar, O. Keisar, and D.M DiSegni. 2015. Benefits of growing potatoes under cover crops in a Mediterranean Climate. Agriculture, Ecosystems and Environment Journal 211:1-9.

Eustehues, K., C. Rumpel, M. Kleber, and I. Kögel-Knaber. 2003. Stabilisation of soil organic matter by interactions with minerals as revealed by mineral dissolution and oxidative degradation. Organic Geochemistry Journal 34:1591-1600
FAO-ISRIC-ISSS (Food and Agriculture Organization of the United Nations, International Soil Reference and Information Centre, International Society for Soil Science).1998. World Reference Base for Soil Resources, ISBN 92-5-104141-5. Rome: FAO, International Soil Reference and Information Centre.

FAO/UNESCO (The Food and Agriculture Organization of the United Nations/The United Nations Educational, Scientific and Cultural Organisation). 1971-1981. Soil Map of the World 1:5000000, vol. I-X, ISBN, 92-3-101364-0. Rome: The Food and Agriculture Organization of the United Nations.

Finney, H.J. 1984. The effect of crop covers on rainfall characteristics and splash detachment. Journal of Agricultural Engineering Research 29:337-343.

Gachene, C.K.K., N.J. Jarvis, and J.P. Mbuvi. 1997. Soil erosion effects on soil properties in a highland area of Central Kenya. Soil Science Society of America Journal 61:559-564.

Gachene, C.K.K., H. Linner, J.N. Jarvis, and J.P. Mbuvi. 2001 Field assessment of the effect of cumulative soil loss on soil productivity. East African Agricultural and Forestry Journal 67(2):129-145

Golchin, A., J.A. Baldock, and J.M. Oades. 1998. A model linking organic matter decomposition, chemistry, and aggregate dynamics. In Soils Processes and the Carbon Cycle (Advances in Soil Science), ed. R. Lal,J.M. Kimble, and R.F. Follet, 245-266. Boca Raton, FL: CRC Press.

Golchin, A., J.M. Oades, J.O. Skjemstad, and P. Clarke. 1994. Study of free and occluded particulate organic-matter in soils by solid-state C-13 CP/MAS NMR-spectroscopy and scanning electron-microscopy. Australian Journal of Soil Research 32:285-309.

Guggenberger, G., B.T. Christensen, and W. Zech. 1994. Land-use effects on the composition of organic matter in particle-size separates of soil: I. Lignin and carbohydrate signature. European Journal of Soil Science 45:449-458.

Haregeweyn, N., J. Poesen, J. Deckers, J. Nyssen, M. Haile, G. Govers, G. Verstraeten, and J. Moeyersons. 2008. Sediment-bound nutrient export from micro-dam catchments in northern Ethiopia. Land Degradation Development 19:136-152.

Jacinthe, P.A., R. Lal, and J.M. Kimble. 2002. A simulation study of carbon dioxide evolution in runoff from longterm no-till and plowed soils. Soil Tillage Research Journal 66:23-33.

Janzen, H.H. 2004. Carbon cycling in earth systems: A soil science perspective. Agriculture, Ecosystems and Environment Journal 104:399-417.

Kapkiyai, J., N.K. Karanja, J.N. Qureshi, P.C. Smithson, and P.L. Woomer. 1999. Soil organic matter and nutrient dynamics in a Kenyan nitisols under long-term fertilizer and organic input management. Soil Biology and Biochemistry 31:1773-1782.

Keeney, D.R., and D.W. Nelson. 1982. Nitrogen Inorganic Forms. In Methods of Soil Analysis, Part 2, Agronomy Monograph No. 9, ed. A.L. Page, R.H. Miller, and D.R. 
Keeney, 643-698. Madison, WI: American Society of Agronomy and Soil Science Society of America.

Khisa, P., C.K.K. Gachene, N.K. Karanja, and J.G. Mureithi. 2002. The effect of post-harvest crop cover on soil erosion in a maize-legume based cropping system in Gatanga, Kenya. Journal of Agriculture in the Tropics and Subtropics 103:17-28.

Li, Y., J. Jiao, Z. Wang, B. Cao, Y. Wei, and S. Hu. 2016. Effects of revegetation on soil organic carbon storage and erosion-induced carbon loss under extreme rainstorms in the hill and gully region of the Loess Plateau. International Journal of Environmental Research and Public Health 13:456.

Li, G.-1., and X.-m. Pang. 2014. Difference in organic carbon contents and distributions in particle-size fractions between soil and sediment on the southern Loess Plateau, China. Journal of Mountain Science 11:717-726

Ma, B.,Y. Liu, X. Liu, F. Ma, F.Wu, and Z. Li. 2015. Soil splash detachment and its spatial distribution under corn and soybean cover. Catena 127:142-151.

Martínez-Mena, M., J. López, M. Almagro, J. Albaladejo, V. Castillo, R. Ortiz, and C. Boix-Fayos. 2012. Organic carbon enrichment in sediments: Effects of rainfall characteristics under different land uses in a Mediterranean area. Catena 94:36-42.

Martínez-Mena, M., J. López, M. Almagro, C. Boix-Fayos, and J. Albaladejo. 2008. Effect of water erosion and cultivation on the soil carbon stock in a semiarid area of South-East Spain. Soil and Tillage Research 99:119-129.

Miao, Q.A., C.G. Cao, J.P. Wang, C. Gao, and C.F. Li. 2011. Effects of different crop systems on soil splash erosion from sloping land in Danjiangkou Reservoir region. Science of Soil and Water Conservation 9:11-14.

Morgan, R.P.C. 1978. Field studies of rainsplash erosion. Earth Surface Processes and Landforms 3:295-299.

Nadeu, E., J. de Vente, M. Martínez-Mena, and C. BoixFayos. 2011. Exploring particle size distribution and organic carbon pools mobilized by different erosion processes at the catchment scale. Journal of Soils and Sediments 11:667-678.

Nelson, D.W., and LE. Sommers. 1982. Total carbon, organic carbon and organic matter. In Methods of Soil Analysis, Part 2, 2nd edition, Agronomy Monograph No. 9, ed. A.L. Page, R.H. Miller, and D.R. Keeney, 102-129. Madison, WI: American Society of Agronomy and Soil Science Society of America Press.

Owens, L.B., R.W. Malone, D.L. Hothem, G.C. Starr, R. Lal. 2002. Sediment carbon concentration and transport from small watersheds under various conservation tillage practices. Soil Tillage Research 67:65-73.

Palis, R.G., C.W. Rose, and P.G. Saffigna. 1997. Soil erosion and nutrient loss. II Changes in the enrichment ratio of total nitrogen and organic carbon under rainfall detachment and enrichment. Australian Journal of Soil Research 35:907-924.
Payne, R.W., S.A. Harding, D.A. Murray, D.M. Soutar, D.B. Baird, A.I. Glaser, I.C. Channing, S.J. Welham, A.R. Gilmour, R. Thompson, and R. Webster. 2009. GenStat Release 12 Reference Manual, Part 2 Directives. Hemel Hempstead, UK:VSN International.

Pikul, J.J.L., S. Osborne, M. Ellsbury, and W. Riedell. 2007. Particulate organic matter and water-stable aggregation of soil under contrasting management. Soil Science Society of America Journal 71:766-776.

Pimentel, D., and M. Burgess. 2013. Soil erosion threatens food production. Journal of Agriculture 3:443-463.

Puget, P., C. Chenu, and J. Balesdent. 2000. Dynamics of soil organic matter associated with particle-size fractions of water-stable aggregates. European Journal of Soil Science 51:595-605.

Quinton, J.N., J.A. Catt, and T.M. Hess. 2001. Selective removal of phosphorus from soil: Is event size important? Journal of Environmental Quality 30:538-545.

Rhoton, F.E., W.E. Emmerich, D.C. Goodrich, S.N. Miller, and D.S. McChesney. 2006. Soil geomorphological characteristics of a semiarid watershed: influence on carbon distribution and transport. Soil Science Society of America Journal 70:1532-1540.

Roscoe, R., and P. Buurman. 2003. Tillage effects on soil organic matter in density fractions of a Cerrado Oxisol. Soil and Tillage Research 70:107-119.

Schiettecatte, W., D. Gabriels, W. Cornelis, and G. Hofman. 2008. Enrichment of organic carbon in sediment transport by interrill and rill erosion processes. Soil Science Society of America Journal 72:50-55.

Schmidt, H., B. Hornetz, and C.A. Shisanya. 2006. Natural Conditions and Farm Information Volume II, part 2/B2. In Farm Management Handbook of Kenya, 2nd edition. Nairobi, Kenya: Ministry of Agriculture/GTZ.

Six, J., R.T. Conant, E.A. Paul, and K. Paustian. 2002. Stabilization mechanisms of soil organic matter: Implications for C- saturation of soils. International Journal on Plant-Soil Relations 241:155-176.

Six, J., G. Guggenberger, K. Paustian, L. Haumaier, E.T. Elliott, and W. Zech. 2001. Sources and composition of soil organic matter fractions between and within soil aggregates. European Journal of Soil Science 52:607-618.

Sohi, S.P., N. Mahieu, J.R.M. Arah, D.S. Powlson, B. Madari, and J.L. Gaunt. 2001. A procedure for isolating soil organic matter fractions suitable for modeling. Soil Science Society of America Journal 65:1121-1128.

Sombroek, W.G., H.M.H. Braun, and B.J.A. van der Pouw. 1982. Kenya Soil Survey:The Exploratory Soil Map and Agro-climate Zone Map of Kenya, scale 1:1,000,000. Nairobi, Kenya: Ministry of Agriculture-National Agricultural Laboratories.

Von Lützow, M., I. Koegel-Knabner, K. Ekschmitt, E. Matzner, G. Guggenberger, B. Marschner, and H. Flessa. 2006. Stabilization of organic matter in temperate soils: Mechanisms and their relevance under different soil conditions: A review. European Journal of Soil Science 57:426-445.

Wang, X., E.L.H. Cammeraat, P. Romeijn, and K. Kalbitz. 2014. Soil organic carbon redistribution by water erosion-The role of $\mathrm{CO}_{2}$ emissions for the carbon budget. PLOS One 9:96-299.

Wang, Z.G., G. Govers, A. Steegen, W. Clymans, A. Van den Putte, C. Langhans, R. Merckx, and K. Van Oost. 2010. Catchment-scale carbon redistribution and delivery by water erosion in an intensively cultivated area. Geomorphology 124:65-74.

Wang, Z.G., G. Govers, K. Van Oost, W. Clymans, A. Van den Putte, and R. Merckx. 2013. Soil organic carbon mobilization by interrill erosion: Insights from size fractions. Journal of Geophysical Research 118:348-360.

Wendelaar, F.E., and A.N. Purkins. 1979. Recording soil loss and runoff from erosion research field plots. Research Bulletins No. 24. Salisburry, Rhodesia: Department of Conservation and Extension.

Wischmeier, W.H., and D.D. Smith. 1958. Rainfall energy and its relationship to soil loss. EOS, Transactions American Geophysical Union 39:285-291.

Yamashita, T., H. Flessa, B. John, M. Helfrich, and B. Ludwig. 2006. Organic matter in density fractions of water-stable aggregates in silty soils: Effect of land use. Soil Biology and Biochemistry 38:3222-3234.

Zhang, J.H., T.A. Quine, S.J. Ni, and F.L. Ge. 2006. Stocks and dynamics of SOC in relation to soil redistribution by water and tillage erosion. Global Change Biology 12:1834-1841 